\title{
BRIEF REPORTS
}

\section{INTERLOCKING TIBIAL NAILING WITHOUT AN IMAGE INTENSIFIER}

\section{D. TANNA}

The use of locked nailing for tibial fractures has increased, but most methods involve the use of image intensifiers (Court-Brown 1990; Müller et al 1990; Paige Whittle et al 1992). In India, $98 \%$ of hospitals do not have image intensifiers. A method is reported for locked tibial nailing in these circumstances, using hollow tubular nails with no slit and anteroposterior (AP) holes for the locking screws.

Technique. Under tourniquet, the patient is placed supine with the leg free. A patellar-tendon-splitting approach is used to insert the nail over a guide wire without reaming, using a specially designed insertion handle which can control rotation. Care is taken to keep the locking holes in perfect $\mathrm{AP}$ direction.

When the nail has been fully introduced another nail is placed over the skin parallel to the first one to act as a jig and Kirschner wires are passed through the holes in it to mark small impressions on the anterior cortex of the tibia. Radiographs are taken (Fig. 1).

The Kirschner wires are removed and skin incisions made to locate the small impressions made by the wires on the bone; the radiographs are then studied to decide the exact point of entry in relation to the wires. A $4.5 \mathrm{~mm}$ drill hole is made at the judged entry point and countersunk to prevent the screw head abrading the tibialis anterior tendon and to improve the view of the nail. A fine sucker and direct vertical light allow the nail to be seen, and a Kirschner wire to be used to locate the hole. Alignment may be improved by small movements of the nail. A $3.2 \mathrm{~mm}$ drill is then passed through the hole in the nail to drill the far cortex. The hole is tapped and a $4.5 \mathrm{~mm}$ screw is inserted. The procedure is repeated for all the other holes.

In six early cases locking had to be abandoned because the holes could not be found, but in all the last 50 cases, good locking has been achieved (Fig. 2).

If the initial hole is not in the right position, a second

D. D. Tanna, MS(Orth), Consultant Orthopaedic Surgeon

Lotus Clinic, Prof. B.Y.L. Nair Hospital, Backbay View, 2nd Floor, 3-A, Mama Parmanand Marg, Near Roxy Cinema, Bombay 400 004, India.

C1994 British Editorial Society of Bone and Joint Surgery 0301-620X/94/4R04 \$2.00

J Bone Joint Surg [Br] 1994; 76-B:670.

Received 6 July 1993; Accepted after revision 11 November 1993

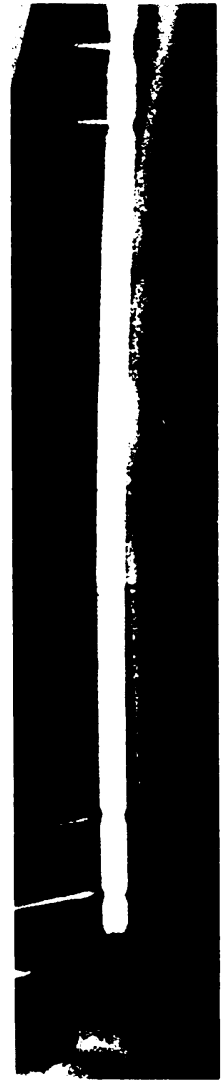

Fig. 1

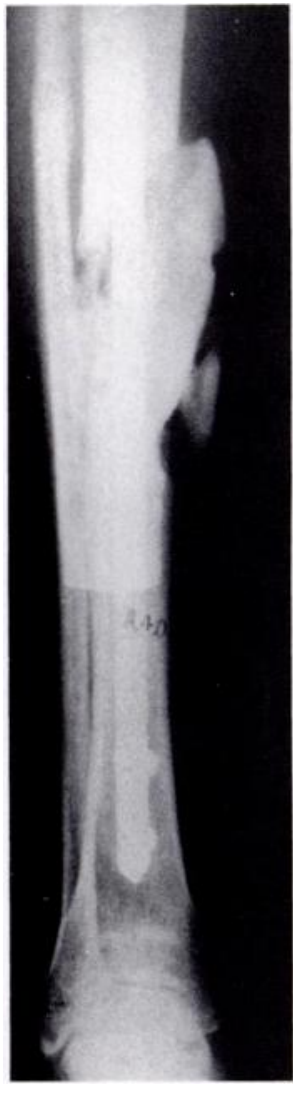

Fig. 2a

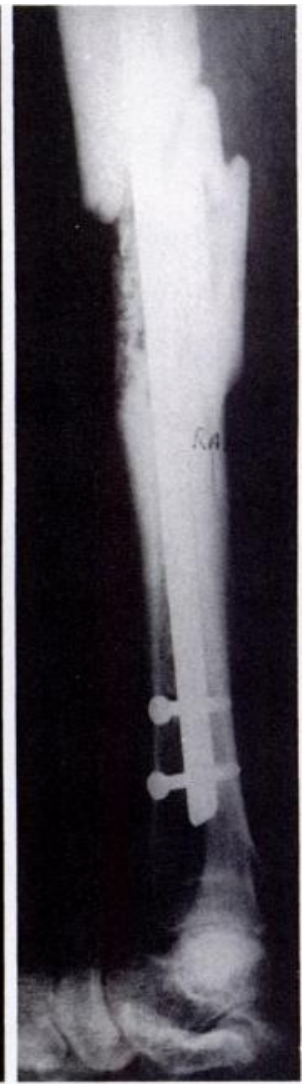

Fig. 2b hole can be drilled. The average time for the procedure was 1.5 hours. If closed reduction was not possible an open reduction was done.

This technique has enabled us to use locking nails successfully without sophisticated devices like image intensifiers, flexible reamers and special jigs.

No benefits in any form have been received or will be received from a commercial party related directly or indirectly to the subject of this article.

\section{REFERENCES}

Court-Brown CM, Christie J, McQueen MM. Closed intramedullary tibial nailing: its use in closed and type I open fractures. J Bone Joint Surg [Br] 1990; 72-B:605-11.

Müller ME, Allgöwer M, Schneider R, Willenegger H. Manual of internal fuxation: techniques recommended by the AO-ASIF group. Third ed. Berlin, etc: Springer-Verlag, 1990:332-65.

Paige Whittle A, Russell TA, Taylor JC, Lavelle DG. Treatment of open fractures of the tibial shaft with the use of interlocking nailing without reaming. J Bone Joint Surg [Am] 1992; 74-A:1162-71. 